\title{
Hypospadias surgery in children: improved service model of enhanced recovery pathway and dedicated surgical team
}

\author{
YS Wong, Kristine KY Pang, YH Tam *
}

This article was published on 21 May 2018 at www.hkmj.org.

\section{A B S T R A C T}

Introduction: Children in Hong Kong are generally hospitalised for 1 to 2 weeks after hypospadias repairs. In July 2013, we introduced a new service model that featured an enhanced recovery pathway and a dedicated surgical team responsible for all perioperative services. In this study, we investigated the outcomes of hypospadias repair after the introduction of the new service model.

Methods: We conducted a retrospective study on consecutive children who underwent primary hypospadias repair from January 2006 to August 2016, comparing patients under the old service with those under the new service. Outcome measures included early morbidity, operative success, and completion of enhanced recovery pathway.

Results: The old service and new service cohorts comprised 176 and 126 cases, respectively. There was no difference between the two cohorts in types of hypospadias and surgical procedures performed. The median hospital stay was 2 days in the new service cohort compared with 10 days in the old service cohort $(\mathrm{P}<0.001)$. Patients experienced less early morbidity (5.6\% vs $15.9 \% ; \mathrm{P}=0.006)$ and had a lower operative failure rate $(20.2 \%$ vs $44.2 \%$;

$\mathrm{P}<0.001)$ under the new service than the old service.
Multivariable analysis revealed that the new service significantly reduced the odds of early morbidity (odds ratio $=0.35,95 \%$ confidence interval $=0.15-0.85$; $\mathrm{P}=0.02$ ) and operative failure (odds ratio $=0.32$, 95\% confidence interval=0.17-0.59; $\mathrm{P}<0.001$ ) in comparison with the old service. Of the new service cohort, 111(88.1\%) patients successfully completed the enhanced recovery pathway.

Conclusions: The enhanced recovery pathway can be implemented safely and effectively to primary hypospadias repair. A dedicated surgical team may play an important role in successful implementation of the enhanced recovery pathway and optimisation of surgical outcomes.

\section{Hong Kong Med J 2018;24:238-44}

DOI: $10.12809 / \mathrm{hkmj} 177039$

YS Wong, FHKAM (Surgery)

KKY Pang, FHKAM (Surgery)

YH Tam *, FHKAM (Surgery)

Division of Paediatric Surgery and Paediatric Urology, Department of Surgery, Prince of Wales Hospital, The Chinese University of Hong Kong, Shatin, Hong Kong

* Corresponding author: pyhtam@surgery.cuhk.edu.hk

\section{New knowledge added by this study}

- Children can be discharged early from hospital after primary hypospadias repairs, regardless of the severity of the hypospadias and the surgical techniques used.

- Improved operative success of hypospadias repair may be achieved by dedicated hypospadias surgeons.

Implications for clinical practice or policy

- Primary hypospadias repair in children can be considered as short-stay surgery.

- Tertiary centres for hypospadias may consider concentration of hypospadias repairs among a few dedicated surgeons.

\section{Introduction}

Hypospadias is a congenital abnormality of the external genitalia in boys, and is defined as an arrest in the embryological development of the urethra, foreskin, and ventral aspect of the penis. ${ }^{1}$ Hypospadias is characterised by abnormal foreskin with a dorsal hood and an ectopic urethral meatus, which can be located anywhere from the ventral aspect of the glans penis, along the penile shaft, within the scrotum, to the perineum (Fig 1). Hypospadias can be classified broadly into distal, mid-shaft, or proximal types, with the proximal type being the most severe form. In general, more severe forms of hypospadias are associated with a higher incidence and severity of penile ventral curvature (chordee). ${ }^{1}$

Hypospadias repair is generally recommended in early childhood for improved function and cosmesis. ${ }^{2}$ Although advances in surgical techniques have resulted in favourable outcomes with high success rates for distal hypospadias repair, ${ }^{3}$ proximal hypospadias repair remains challenging, and 
complication rates have been reported to be as high as over $50 \% .{ }^{4}$ Postoperatively, the urethral catheter is usually left in place for free drainage for 5 to 7 days in distal repair ${ }^{5}$ and from 10 to 14 days in proximal repair. ${ }^{6}$ In many parts of the world, including North America, patients generally have a very short stay in hospital and are discharged home with urethral catheters in situ. ${ }^{7}$ In contrast, conventional practice in Hong Kong has been to provide in-patient care after hypospadias surgery until removal of the urethral catheter.

The Division of Paediatric Surgery and Paediatric Urology at the Prince of Wales Hospital has been a tertiary referral centre for hypospadias surgery for over two decades. We introduced a new service (NS) model in July 2013, which featured the establishment of a dedicated surgical team and the implementation of an enhanced recovery pathway (ERP). The present study aimed to compare the outcomes of the NS model with those of the old service (OS) model. We hypothesised that ERP implementation by a dedicated surgical team would reduce the risk of early morbidity and increase the operative success of hypospadias repair.

\section{Methods}

\section{Patients}

A historical cohort study was conducted on consecutive patients younger than 18 years who underwent primary repair of hypospadias in our centre from January 2006 to August 2016. The patients were identified using both the ICD-10 (International Classification of Diseases, 10th revision) code related to hypospadias surgery and the registry of operative procedures entry in operating theatres. We used ICD-10 code 752.61, which covered the diagnosis of various types of hypospadias, as well as codes 58.45 and 58.46, which covered various techniques of hypospadias repairs. The patients underwent either one-stage tubularised incised plate (TIP) repair $^{5,8}$ (Fig 2), or two-stage

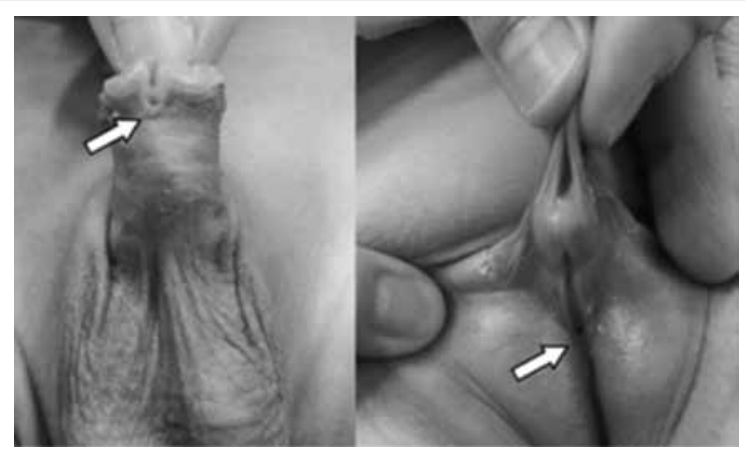

FIG I. Distal hypospadias (left) and proximal hypospadias (right)

Ectopic urethral meatus are indicated by arrows

\section{兒童尿道下裂手術：快速恢復路徑及專責手術 團隊的改良服務模式 \\ 黃婉珊、彭潔儀、譚煜謙}

引言：在香港, 兒童在修復尿道下裂後普遍留院 1 至 2 星期。我們於 2013 年7月引入全新服務模式, 這模式包括快速恢復路徑及一隊負責 所有手術周邊服務的專責手術團隊。本研究檢視引入新服務模式後修 復尿道下裂的結果。

方法：我們進行回顧研究, 檢視2006年1月至2016年8月期間接受原 發性尿道下裂修復的兒童, 並在新舊服務模式下作出比較。結果測量 包括早期併發症率、手術成功率, 以及能否完成快速恢復路徑。

結果：舊服務及新服務模式分別涉及176及126宗病例。兩組的尿道 下裂種類及手術程序並無分別。新服務的留院日期中位數是 2 天, 而舊服務則須 10 天 $(\mathrm{P}<0.001)$ 。在新服務模式下, 病人早期併發 症率 $(5.6 \%$ 比 $15.9 \%, \mathrm{P}=0.006)$ 和手術失敗率 $(20.2 \%$ 比 $44.2 \%$, $\mathrm{P}<0.001)$ 均較接受舊服務病人有所改善。多元數據分析結果顯示對 比舊服務, 新服務大幅減低早期併發症（比值比 $=0.35,95 \%$ 置信區 間：0.15-0.85, $\mathrm{P}=0.02$ ) 和手術失敗（比值比 $=0.32,95 \%$ 置信區 間：0.17-0.59，P<0.001）的可能性。新服務中, 111 宗 $(88.1 \%)$ 病 例成功完成快速恢復路徑。

結論：快速恢復路徑可安全和有效於處理尿道下裂修復時推行。一隊 專責手術團隊可在成功推行快速恢復路徑和完善手術結果中扮演重要 角色。

preputial flap repair ${ }^{9}$ (Fig 3), as these two techniques had been our standard practice for primary repair of hypospadias from distal to proximal types during the study period. We excluded reoperative hypospadias repairs and repairs with buccal mucosal graft (BMG). Reoperative hypospadias surgery is highly variable in complexity, involves multiple surgical techniques, and is usually investigated separately from primary hypospadias surgery in literature. Children who undergo BMG harvest are generally not considered suitable for early hospital discharge. Moreover, BMG is used rarely in hypospadias surgery, and only under special circumstances. We also excluded minor hypospadias repairs by meatal advancement with



FIG 2. Before (left) and after (right) one-stage tubularised incised plate repair

Ectopic urethral meatus are indicated by arrows 


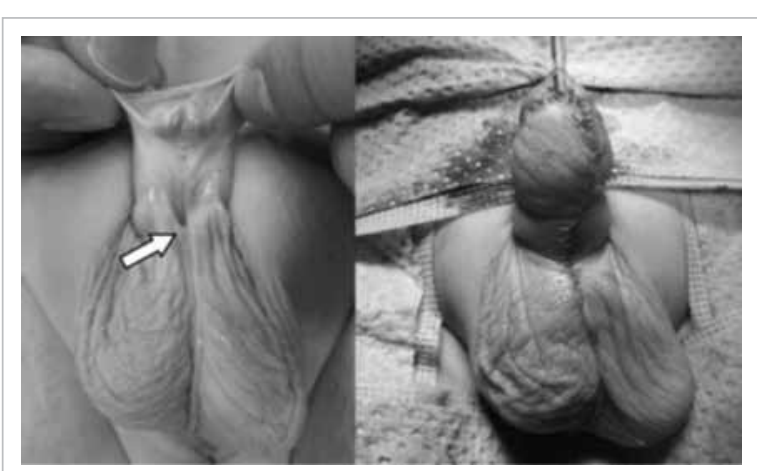

FIG 3. Before (left) and after (right) two-stage preputial flap repair

Ectopic urethral meatus are indicated by arrows

glansplasty or meatoplasty alone, as such procedures did not require prolonged urethral catheterisation.

\section{New service model versus old service model}

In this study, we assigned patients to two cohorts. The OS cohort was the control cohort comprising patients on whom we operated from January 2006 to June 2013. All the patients in this cohort remained as in-patients until removal of the urethral catheter and received intravenous antibiotics and regular wound care by medical staff in the postoperative period. Six specialist paediatric surgeons were involved in performing the repairs in the OS cohort. The NS cohort comprised patients who underwent surgery in July 2013 or thereafter. Patients in the NS cohort were routinely discharged on postoperative day 2 or, rarely, on postoperative day 3 , with their urethral catheters in situ. The dedicated surgical team comprising three (initially only two) specialist paediatric surgeons who subspecialised in paediatric urology provided all perioperative services, including handling of the consent process, surgical repairs, postoperative demonstration of wound care, and explanation of the discharge plan. Parents or main caregivers were instructed to perform saline irrigation to the penile wound at home 3 to 4 times per day. Patients received oral antibiotics and were scheduled to return in a day visit for removal of urethral catheters by a member of the dedicated team. Parents were instructed to call the ward to arrange an unplanned consultation visit if necessary. After urethral catheter removal, patients were followed up at 2 to 4 weeks, 3 months, 6 to 9 months, and then yearly thereafter.

\section{Outcome measures}

Medical records were retrospectively reviewed and data were collected by the authors, who were not blinded to the type of service model. Data collected were age at time of surgery, type of hypospadias, type of surgical repair, early morbidity, length of hospital stay (LOS), unplanned hospital visits, and followup evaluation for long-term complications. Data on the types of hypospadias and surgical techniques were based on the operative findings and surgical procedures documented in the operative records. The presence of any early morbidity was based on investigation results (including urine/wound swab culture) and/or documentations of urethral catheter dislodgement, wound bleeding, or wound gaping in the early postoperative period when the urethral catheter was in situ. The presence of any long-term complications was based on the findings in the latest follow-up visit, or any reintervention/reoperation records subsequent to the primary surgery. When collecting data, we tried to minimise potential bias regarding long-term complications by defining such complications as meatal stenosis, neourethra dehiscence, urethral fistula, urethral stricture or diverticulum, and significant recurrent chordee. All of these long-term complications required reintervention/reoperation and were documented if present.

Primary outcomes of interest were early morbidity and operative failure. Early morbidity was defined by the presence of one or more of the following conditions when the urethral catheter was still in situ: urinary tract infection, catheter dislodgement, and wound-related events (bleeding/ infection/gaping). In the OS cohort, early morbidity was detected during the hospitalisation period after hypospadias repair. In the NS cohort, early morbidity was detected at the time of urethral catheter removal or during unplanned hospital visits before the scheduled date of urethral catheter removal.

Successful or failed repair was determined during follow-up in those who had undergone TIP repair or had completed both stages of the two-stage repair. Operative failure was defined as the development of one or more of the longterm complications that required reoperation or reintervention. The secondary outcome measure was the successful completion rate of ERP. Failure of ERP was defined as any unplanned hospital visit earlier than the scheduled date for urethral catheter removal. Failure was further subdivided into day visit or overnight stay.

\section{Statistical analysis}

Discrete variables were expressed as percentage frequency, whereas continuous variables were reported as mean with standard deviation or median with interquartile range (IQR). The two cohorts were compared using Chi squared, Fisher's exact, Student's $t$, and Mann-Whitney $U$ tests, as appropriate. Using the outcomes of early morbidity and operative failure, multivariable analysis was performed using a logistic regression model by the enter method, which estimated the odds ratios (ORs) and 95\% 
confidence intervals (95\% CIs) of potential associated factors, including age at the time of surgery, type of hypospadias, type of surgical repair, and the service model. Statistical analysis was performed with SPSS (Windows version 23; IBM Corp, Armonk [NY], United States). A two-tailed P value of $<0.05$ was considered to be statistically significant. Based on type I error of 0.05 and power of $0.8,82$ to 152 cases in each cohort would be required to show any twotailed significant difference in the operative failure rates with a difference of $15 \%$ to $20 \%$ between the two cohorts.

\section{Results}

There were 302 major primary hypospadias repairs (OS cohort=176; NS cohort=126) eligible for inclusion in the study. We identified 107 cases of reoperative hypospadias repairs and one case of BMG during the study period; these were excluded from this study. No patients were lost to the first follow-up examination after urethral catheter removal. The median follow-up durations of the OS and NS cohorts were 32 (IQR, 20-58) and 20 (IQR, 14-30) months, respectively $(\mathrm{P}<0.001)$.

Of the NS cohort, 111 (88.1\%) patients successfully completed the ERP. Of the 15 patients who failed to complete ERP, 11 (8.7\% of total) returned earlier in an unplanned day visit for wound assessment; these patients only required reassurance without any intervention. Four patients $(3.2 \%$ of total) required additional overnight hospital stay. Reasons for additional overnight stay were minor wound bleeding $(n=1)$, dislodgement of urethral catheter $(n=2)$, and social reasons $(n=1)$. The patient who failed ERP for social reasons was an orphan, and staff at the orphanage found it difficult to perform wound care at their institution.

Table 1 summarises the findings comparing patient characteristics and early morbidity between the two cohorts. The median age at the time of surgery was older in the OS than the NS cohort $(\mathrm{P}<0.001)$. There was no difference between the two groups in type of hypospadias, type of surgical procedures, and time interval between surgery and urethral catheter removal. The median LOS was 2 days in the NS cohort versus 10 days in the OS cohort $(\mathrm{P}<0.001)$. Patients in the NS cohort experienced less early morbidity than those in the OS cohort (5.6\% vs 15.9\%; $\mathrm{P}=0.006)$.

Excluding patients who had received only the first stage of a two-stage repair, 138 and 109 patients of the OS and NS cohort, were eligible for assessment of operative success, respectively. Patients in the NS cohort had a lower operative failure rate than those in the OS cohort (20.2\% vs $44.2 \%$; $\mathrm{P}<0.001)$. Specifically, patients in the NS cohort had a lower incidence of urethral fistula and dehiscence than patients in the OS cohort $(\mathrm{P}=0.002$ and 0.001$)$; there were no differences in the other complications (Table 2).

In the multivariable analysis, the NS model was the only factor that was independently associated

TABLE I. Results of univariable analysis comparing baseline characteristics and early morbidity of the two cohorts

\begin{tabular}{|c|c|c|c|}
\hline & $\begin{array}{l}\text { Old service cohort } \\
\qquad(n=176)\end{array}$ & $\begin{array}{c}\text { New service cohort } \\
(n=126)\end{array}$ & $P$ value \\
\hline Age at the time of surgery, median (IQR), mo & $36(21-50)$ & $22(15-38)$ & $<0.001$ \\
\hline Type of hypospadias, No. (\%) & & & 0.16 \\
\hline Distal & $31(17.6)$ & $30(23.8)$ & \\
\hline Mid-shaft & $35(19.9)$ & $16(12.7)$ & \\
\hline Proximal & $110(62.5)$ & $80(63.5)$ & \\
\hline Type of hypospadias repair, No. (\%) & & & 0.16 \\
\hline One-stage tubularised incised plate & $105(59.7)$ & $87(69.0)$ & \\
\hline \multicolumn{4}{|l|}{ Two-stage preputial flap repair } \\
\hline First stage & $38(21.6)$ & $17(13.5)$ & \\
\hline Second stage & $33(18.8)$ & $22(17.5)$ & \\
\hline Duration with urethral catheter in situ, mean (SD), $d$ & $10.2(2.9)$ & $10.7(2.8)$ & 0.1 \\
\hline Length of hospital stay, median (IQR), d & $10(8-12)$ & $2(2-2)$ & $<0.001$ \\
\hline Follow-up, median (IQR), mo & $32(20-58)$ & $20(14-30)$ & $<0.001$ \\
\hline Early morbidity, No. (\%) ${ }^{*}$ & $28(15.9)$ & $7(5.6)$ & 0.006 \\
\hline Urinary tract infection & $3(1.7)$ & 0 & \\
\hline Catheter dislodgement & $2(1.1)$ & $4(3.2)$ & \\
\hline Wound-related (bleeding/infection/gaping) & $24(13.6)$ & $3(2.4)$ & \\
\hline
\end{tabular}

Abbreviations: IQR = interquartile range; $\mathrm{SD}=$ standard deviation

* One patient in the old service cohort had more than one morbidity 
with reduced odds of early morbidity $(\mathrm{OR}=0.35$, 95\% $\mathrm{CI}=0.15-0.85 ; \mathrm{P}=0.02)$. The NS model was also associated with reduced odds of operative failure $(\mathrm{OR}=0.32,95 \% \mathrm{CI}=0.17-0.59 ; \mathrm{P}<0.001)$ compared with the OS model. Compared with proximal hypospadias, distal hypospadias had reduced odds for operative failure $(\mathrm{OR}=0.14,95 \% \mathrm{CI}, 0.06-0.37$; $\mathrm{P}<0.001)$. Age at the time of surgery and surgical techniques were not associated with any difference in operative success (Table 3).

\section{Discussion}

The conventional practice of keeping patients in hospital until urethral catheter removal after hypospadias surgery is well reflected from the first annual Surgical Outcome Monitoring and Improvement Programme Report in 2008/09 to the fifth report in 2012/13 issued by the Hong Kong Hospital Authority. ${ }^{10-14}$ The median LOS after hypospadias surgery performed in Hospital Authority hospitals ranged from 9 to 11 days from 2008 to $2013 .{ }^{10-14}$ It was a traditionally held belief that Hong Kong parents would not be sufficiently competent to provide proper wound care at home, and that surgical outcomes would be adversely affected if patients were discharged from hospital with the urethral catheter in situ. There was also concern that Hong Kong parents would not welcome the offer of early hospital discharge, given the reality that the actual costs billed to parents for in-patient service in Hospital Authority hospitals are relatively insignificant, compared with other parts of the world where medical insurance covers only very short inpatient care after hypospadias surgery. The present study was the first in Hong Kong to investigate the outcomes of hypospadias surgery after the introduction of an ERP. It is important to note that our findings do not reflect purely the effect of ERP but the effect of an NS model that features ERP implementation by a dedicated surgical team.

Our findings demonstrate that ERP can be applied effectively and safely to all children who undergo primary hypospadias repair, regardless of the severity and type of hypospadias. Since its introduction, we have offered ERP to 126 consecutive patients and none of the parents or caregivers have declined the offer. Only one patient discontinued ERP for social reasons, as that child was an institutionalised orphan. Penile wound care does not require special skills and involves only wound irrigation with normal saline or clean water a few times daily. Patients can also be bathed with the urethral catheters in situ. Adequate preoperative

TABLE 2. Results of univariable analysis comparing operative failure rates of the two cohorts*

\begin{tabular}{lccc}
\hline & Old service cohort $(\mathbf{n = 1 3 8 )}$ & New service cohort $(\mathbf{n}=\mathbf{1 0 9 )}$ & $\mathbf{P}$ value \\
\hline Overall operative failuret & $61(44.2)$ & $22(20.2)$ & $8(7.3)$ \\
Urethral fistula & $30(21.7)$ & $1(0.9)$ & 0.001 \\
Urethral dehiscence & $16(11.6)$ & $13(11.9)$ & 0.002 \\
Meatal stenosis & $12(8.7)$ & $2(1.8)$ & 0.40 \\
Urethral stricture/diverticulum & $4(2.9)$ & $1(0.9)$ & 0.44 \\
Significant ventral curvature & $3(2.2)$ & & 0.59 \\
\hline
\end{tabular}

Data are shown as No. (\%) of patients, unless otherwise specified

$\dagger$ Defined as the No. of patients with $\geq$ I long-term complications

TABLE 3. Results of multivariable analysis of independent predictors for early morbidity and operative failure*

\begin{tabular}{|c|c|c|c|c|}
\hline & Early morbidity & P value & Operative failure & $P$ value \\
\hline Age at time of surgery & $1.01(0.99-1.03)$ & 0.10 & $1.01(0.99-1.02)$ & 0.146 \\
\hline \multicolumn{5}{|l|}{ Type of hypospadias } \\
\hline Distal & $0.47(0.13-1.05)$ & 0.24 & $0.14(0.06-0.37)$ & $<0.001$ \\
\hline Mid-shaft & $0.69(0.21-2.21)$ & 0.53 & $0.49(0.23-1.08)$ & 0.78 \\
\hline Proximal & Reference $=1$ & & Reference $=1$ & \\
\hline \multicolumn{5}{|l|}{ Type of hypospadias repair } \\
\hline One-stage tubularised incised plate & $0.86(0.36-2.01)$ & 0.73 & $1.01(0.48-2.12)$ & 0.98 \\
\hline Two-stage preputial flap repair & Reference $=1$ & & Reference $=1$ & \\
\hline \multicolumn{5}{|l|}{ Service model } \\
\hline Old service & Reference $=1$ & & Reference $=1$ & \\
\hline New service & $0.35(0.15-0.85)$ & 0.02 & $0.32(0.17-0.59)$ & $<0.001$ \\
\hline
\end{tabular}

* Data are shown as odds ratio (95\% confidence interval), unless otherwise specified 
counselling and postoperative wound care demonstration by the same surgeons who performed the surgery is the key to promoting the acceptance of ERP among parents.

Almost $90 \%$ of our patients completed ERP successfully. Among those who failed to complete ERP, none had major adverse events that required surgical intervention and, overall, only $3.2 \%$ of patients required additional overnight stay. The median hospital stay of 2 days under the NS model was significantly shorter than the median of 10 days in our OS control cohort. In-patient services are precious resources in our health care system. A much shorter LOS after hypospadias surgery allows for better allocation of health care resources to other service areas in which in-patient care is more indicated.

More importantly, our findings suggest that ERP does not increase early morbidity after primary hypospadias repair. On the contrary, the NS model was the only factor that was found to independently predict a reduced risk of early morbidity. Our finding of an early morbidity rate of $5.6 \%$ in the NS model is in agreement with the $4.9 \%$ reported by a previous study in the United States. ${ }^{15}$ Our finding that most of the early morbidity in the OS model was woundrelated and our observation that, in some of these patients, the wound swab grew Pseudomonas and extended spectrum beta-lactamase Escherichia coli raised the concern of possible hospital-acquired infection. While more evidence is needed to attribute the high early morbidity rate under the OS model solely to the prolonged hospital stay, it follows logically that avoiding unnecessary hospital stay is an effective way to prevent hospital-acquired infection if in-patient care does not give any additional benefits.

We found a better outcome after primary hypospadias repair under the NS versus OS model in both univariable and multivariable analyses. This study not only provides evidence that the implementation of ERP did not reduce operative success, but also demonstrates how our centre has responded to the international trend of concentrating hypospadias repairs among dedicated hypospadias surgeons. ${ }^{2,16,17}$ In recent years, there has been an international call to stop the practice of hypospadias repair by occasional surgeons. Proponents of this view hold that surgeons who perform hypospadias repair should be proficient in using various techniques to correct the full spectrum of hypospadias defects, from distal hypospadias to the most complex proximal type. ${ }^{17,18}$ The preoperative impression of the ectopic meatal position is not a reliable reflection of the severity of hypospadias, and many cases are found to be more complicated intra-operatively. ${ }^{19}$ Under the NS model, we abandoned our policy of allowing all paediatric surgical specialists to perform hypospadias surgery; instead, all hypospadias repairs were concentrated among the three specialists who subspecialised in paediatric urology.

We believe the improved operative success under the NS model is attributable to the establishment of the dedicated team, which has also introduced some technical modifications in the existing techniques. ${ }^{20}$ Our overall failure rate of $20.2 \%$ of patients requiring reoperation or reintervention in the NS cohort is in agreement with the $18.1 \%$ reported by a national population-based study in the United Kingdom ${ }^{21}$ and the 24.1\% reported by a regional tertiary centre in Europe. ${ }^{22}$ Both studies included primary repairs of all types of hypospadias performed by multiple techniques, such as those used in the present study. ${ }^{21,22}$ Previous studies have shown that centres that operate on more than 20 cases per year have a better operative success than those that operate less frequently, ${ }^{21}$ and surgeons who perform 20 primary repairs annually have reduced odds of failure compared with those who perform 10 per year. ${ }^{23}$ Although the minimum number of hypospadias repairs per year a surgeon must perform to be considered competent remains debatable, it is recommended that hypospadias repairs be performed by surgeons who perform a high volume of repairs and are intellectually interested in this subject, with continuous review of their own results. ${ }^{17}$ The current three-member team in our institution strikes a balance between surgical outcomes and other practical issues, such as stable staffing, expertise, training, and succession.

Proximal hypospadias has been known to be associated with a higher failure rate in primary repair and a higher reoperation rate than distal hypospadias. ${ }^{24,25}$ The most recent studies from major centres have unanimously suggested that the failure rate of primary repair of proximal hypospadias has actually been underreported in the literature..$^{6,26,27}$ Our finding of increased odds of failure in primary repair of proximal hypospadias when compared with the distal type is in agreement with the current evidence. We did not find age at the time of surgery and surgical techniques to be independent predictors of repair failure, and our finding is in agreement with other studies. ${ }^{22}$

We acknowledge the limitations of the retrospective nature of our study and the lack of randomisation. Data are lacking on anatomical variations such as quality of urethral plate and glans size, which may have affected the surgical outcomes. Patients were not randomised by the type of recovery programme and the study participants were assigned to the two cohorts according to the service model at the time. Our results could have been confounded by the effect of accumulating experience in hypospadias surgery throughout the study period. Data were collected by investigators who were not blinded to the types of service models; 
therefore, there was potential bias in the data collection process, but inter-rater reliability was not examined. As the ERP was implemented at the same time as the establishment of the dedicated team, these two factors could not be analysed separately. Being the more recent cohort, the patients under the NS model had shorter follow-up duration than those under the OS model. However, our median followup duration of 20 months in the NS cohort compares favourably to that of many published studies. ${ }^{25}$

Despite these limitations, our findings demonstrate the safety and effectiveness of implementing ERP to primary hypospadias repair for the full spectrum of hypospadias severity. A dedicated surgical team may play an important role in the successful implementation of ERP and optimisation of surgical outcomes.

\section{Author contributions}

All authors have made substantial contributions to the concept of this study; acquisition of data; analysis or interpretation of data; drafting of the article; and critical revision for important intellectual content.

\section{Funding/support}

This research received no specific grant from any funding agency in the public, commercial, or not-for-profit sectors.

\section{Declaration}

All authors have no conflicts of interest to disclose. All authors had full access to the data, contributed to the study, approved the final version for publication, and take responsibility for its accuracy and integrity.

\section{Ethical approval}

The study protocol was approved by the Joint Chinese University of Hong Kong-New Territories East Cluster Clinical Research Ethics Committee. The requirement for patient consent was waived by the ethics board.

\section{References}

1. Baskin LS, Ebbers MB. Hypospadias: anatomy, etiology, and technique. J Pediatr Surg 2006;41:463-72.

2. Steven L, Cherian A, Yankovic F, Mathur A, Kulkarni M, Cuckow P. Current practice in paediatric hypospadias surgery; a specialist survey. J Pediatr Urol 2013;9(6 Pt B):1126-30.

3. Wilkinson DJ, Farrelly P, Kenny SE. Outcomes in distal hypospadias: a systematic review of the Mathieu and tubularized incised plate repairs. J Pediatr Urol 2012;8:30712.

4. Long CJ, Canning DA. Hypospadias: are we as good as we think when we correct proximal hypospadias. J Pediatr Urol 2016;12:196.e1-5.

5. Snodgrass WT, Bush N, Cost N. Tubularized incised plate hypospadias repair for distal hypospadias. J Pediatr Urol 2010;6:408-13.

6. Pippi Salle JL, Sayed S, Salle A, et al. Proximal hypospadias: a persistent challenge. Single institution outcome analysis of three surgical techniques over a 10-year period. J Pediatr
Urol 2016;12:28.e1-7.

7. Pohl HG, Joyce GF, Wise M, Cilento BJ Jr. Cryptorchidism and hypospadias. J Urol 2007;177:1646-51.

8. Snodgrass W, Bush N. Tubularized incised plate proximal hypospadias repair: continued evolution and extended applications. J Pediatr Urol 2011;7:2-9.

9. McNamara ER, Schaeffer AJ, Logvinenko $T$, et al. Management of proximal hypospadias with 2-stage repair: 20-year experience. J Urol 2015;194:1080-5.

10. Surgical Outcomes Monitoring \& Improvement Program (SOMIP) report. Volume One: July 2008-June 2009. Hospital Authority, Hong Kong SAR Government; 2010.

11. Surgical Outcomes Monitoring \& Improvement Program (SOMIP) report. Volume Two: July 2009-June 2010. Hospital Authority, Hong Kong SAR Government; 2011.

12. Surgical Outcomes Monitoring \& Improvement Program (SOMIP) report. Volume Three: July 2010-June 2011. Hospital Authority, Hong Kong SAR Government; 2012.

13. Surgical Outcomes Monitoring \& Improvement Program (SOMIP) report. Volume Four: July 2011-June 2012. Hospital Authority, Hong Kong SAR Government; 2013.

14. Surgical Outcomes Monitoring \& Improvement Program (SOMIP) report. Volume Five: July 2012-June 2013. Hospital Authority, Hong Kong SAR Government; 2014.

15. Meyer C, Sukumar S, Sood A, et al. Inpatient hypospadias care: trends and outcomes from the American nationwide inpatient sample. Korean J Urol 2015;56:594-600.

16. Springer A, Krois W, Horcher E. Trends in hypospadias surgery: results of a worldwide survey. Eur Urol 2011;60:1184-9.

17. Snodgrass W, Macedo A, Hoebeke P, Mouriquand PD. Hypospadias dilemmas: a round table. J Pediatr Urol 2011;7:145-57.

18. Malone P. Commentary to "A standardized classification of hypospadias". J Pediatr Urol 2012;8:415.

19. Orkiszewski M. A standardized classification of hypospadias. J Pediatr Urol 2012;8:410-4.

20. Tam YH, Pang KK, Wong YS, et al. Improved outcomes after technical modifications in tubularized incised plate urethroplasty for mid-shaft and proximal hypospadias. Pediatr Surg Int 2016;32:1087-92.

21. Wilkinson DJ, Green PA, Beglinger S, et al. Hypospadias surgery in England: higher volume centres have lower complication rates. J Pediatr Urol 2017;13:481.e1-6.

22. Spinoit AF, Poelaert F, Van Praet C, Groen LA, Van Laecke E, Hoebeke P. Grade of hypospadias is the only factor predicting for re-intervention after primary hypospadias repair: a multivariate analysis from a cohort of 474 patients. J Pediatr Urol 2015;11:70.e1-6.

23. Lee OT, Durbin-Johnson B, Kurzrock EA. Predictors of secondary surgery after hypospadias repair: a population based analysis of 5,000 patients. J Urol 2013;190:251-5.

24. Castagnetti M, El-Ghoneimi A. Surgical management of primary severe hypospadias in children: systematic 20-year review. J Urol 2010;184:1469-74.

25. Pfistermuller KL, McArdle AJ, Cuckow PM. Meta-analysis of complication rates of the tubularized incised plate (TIP) repair. J Pediatr Urol 2015;11:54-9.

26. Stanasel I, Le HK, Bilgutay A, et al. Complications following staged hypospadias repair using transposed preputial skin flaps. J Urol 2015;194:512-6.

27. Long CJ, Chu DI, Tenney RW, et al. Intermediate-term followup of proximal hypospadias repair reveals high complication rate. J Urol 2017;197(3 Pt 2):852-8. 